\title{
AVALIAÇÃO DA COMPETITIVIDADE DE PRODUTOS E SERVIÇOS DE UMA MONTADORA DE AUTOMÓVEIS
}

Diego Augusto de Jesus Pacheco ${ }^{1}$ Junior Silva de Castro ${ }^{2}$ Luciana Wichruk Morais ${ }^{3}$

\section{RESUMO}

Este artigo tem por objetivo verificar a aplicabilidade da matriz de importância e desempenho em uma multinacional do ramo automobilístico. Para tanto, foram analisados critérios competitivos considerados importantes pelos clientes e o desempenho da empresa para tais critérios. A pesquisa foi aplicada a clientes que adquiriram produtos e serviços, e profissionais de áreas estratégicas da empresa. Os dados foram coletados por meio de questionários semiestruturados pelos quais buscou-se identificar a importância e o desempenho na percepção dos clientes e da empresa, nas variáveis que compõem cada critério competitivo. Os principais resultados da pesquisa demonstram que os critérios avaliados pelos clientes, como ganhadores de pedidos que ficaram classificados na zona de ação urgente na matriz, foram: entrega na data prometida, entrega quando o cliente desejar, rapidez na assistência técnica, preço percebido, preocupação com o entendimento do cliente, assistência pós-venda e cumprimento dos prazos acordados. Tais critérios, portanto, deveriam ser considerados prioritários pela empresa na definição de ações de melhoria da competitividade.

Palavras-Chave: TI - Critérios Competitivos. Importância. Desempenho. 


\section{INTRODUÇÃO}

Em um mercado competitivo como o brasileiro, as empresas precisam estar atentas às exigências e necessidades de seus clientes e também às ações de seus concorrentes. Nesse sentido,é possível dizer que é de suma importância para uma empresa a análise completa de seu ambiente, de sua capacidade de produção e operações, e das expectativas de seus clientes. No ramo automobilístico não é diferente. $\mathrm{O}$ fenômeno da globalização, que propiciou a abertura de fronteiras e a integração de mercado, teve como consequência direta o aumento do número de empresas em vários setores da economia. Por conseguinte, os consumidores passaram a ter mais opções de escolha e estão melhor informados e exigentes. (ARAUJO et al., 2011; FUSCO, 1995).

Outro detalhe importante desse novo ambiente globalizado e mais tecnológico consiste na mudança do comportamento do consumidor, que, assim, modificou também a forma de atuar das empresas que estão atentas a esses movimentos. Percebe-se que é fundamental pesquisar o que é importante para os consumidores e como está o desempenho da empresa em relação à concorrência, no que diz respeito aos critérios competitivos valorizados pelos clientes. Com o surgimento de novas opções de compra e da disseminação de informação por meio da internet, televisão e jornais, exige-se das empresas maiores capacidades de flexibilidade e criatividade para atender o mercado consumidor.

No Brasil, O MERCADO AU-

TOMOBILÍSTICO ILUSTRA DE

FORMA CLARA ESSA SITUAÇÃO,

POIS TEM MOSTRADO UMA SÉRIE

DE MUDANÇAS NOS ÚLTIMOS

TEMPOS.

De acordo com Kotler (2000), todas as atividades de negócios relacionadas a produtos e serviços diretamente aos consumidores finais caracterizam-se pela diversidade de segmentos, dentre eles o automobilístico. Nesse sentido, uma das alternativas que pode contribuir para aumentar a competitividade das empresas do setor e ajudar na formulação das estratégias, é a correta priorização dos critérios competitivos na estratégia da empresa.

A abordagem teórica que sustenta a análise deste artigo está relacionada aos critérios competitivos que permitem, mediante a pesquisa, o confronto entre as percepções da empresa e dos clientes, possibilitando, assim, a identificação de quais critérios devem ser priorizados para que a empresa se mantenha no mercado, bem como o a análise do posicionamento na Matriz de Importância x Desempenho proposta por Slack (1993). 


\section{CRITÉRIOS COMPETITIVOS}

Toda e qualquer organização que visa ou não ao lucro trabalha com uma função de operações. A administração de produção e operações tem como definir prioridades e identificar os caminhos para o processo de desenvolvimento de um produto ou serviço. A partir de algumas das definições de administração da produção e operações, faz-se necessário evidenciar o conceito de estratégia, e, ainda, uma das possíveis ferramentas estratégicas aplicadas à gestão de operações: a Matriz Importância x Desempenho.

Apesar de estudos sobre critérios competitivos surgirem recentemente, de acordo com Betto, Ferreira e Talamini (2010), suas origens foram identificadas no final da década de 1960 com alguns padrões comuns para mensurar o desempenho da produção, tais como ciclos menores de entrega do produto, produto com qualidade e confiabilidade, cumprimento da promessa de entrega, habilidade para produzir novos produtos rapidamente, flexibilidade para ajustar mudanças no volume e custos baixos. Segundo os autores, em meados da década de 1980, Hayes e Wheelwright introduziram o termo prioridades competitivas e delinearam quatro dimensões competitivas básicas: preço, qualidade, confiabilidade, e flexibilidade. Hill, no final da década de 1980, desenvolveu um grupo de critérios competitivos que incluiu: preço, produto com qualidade e entrega rápida e confiável.

De acordo Slack (1993), existem cinco critérios competitivos principais:qualidade,rapidez, confiabilidade, flexibilidade e custo, que contribuem para a função produção ser bem sucedida em longo prazo. Diversos autores, como Hayes e Wheelwright (1984), Preto (2003), Slack (1993), Fine e Hax (1985), e Paiva, Carvalho e Fenstersefeir (2009), entre outros, abordam a temática dos critérios competitivos, que nem sempre são chamados dessa forma. Outras nomenclaturas utilizadas pelos autores para abordar os critérios competitivos são: fatores competitivos, prioridades competitivas, objetivos de desempenho e critérios de desempenho.

No entanto, quando se consulta os autores mencionados, verifica-se a similaridade dos critérios, permanecendo a diferença, essencialmente, em terminologias. Segundo o questionamento de Betto, Ferreira e Talamini (2010), se as empresas buscam satisfazer os critérios citados anteriormente, então quais deles constituem os fatores que os clientes utilizam para escolher o fornecedor XeY quando da decisão de compra? Alguns desses fatores devem ter importância maior para certos clientes do que para outros, constituindo-se em critérios competitivos que as empresas devem identificar e priorizar. Para determinados clientes, o critério de escolha mais importante pode ser o preço, para outro, o prazo de entrega ou flexibilidade em aceitar alterações no produto, e assim por diante.

De acordo com Slack (1993), critérios ganhadores de pedidos são os que, direta e significativamente, contribuem para a realização de um negócio ou para conseguir um pedido. Tais critérios são considerados pelos clientes como razões chaves para comprar um produto ou serviço, ou seja, critérios caracterizados como determinantes da escolha do cliente sobre quem será o possível fornecedor. Já os critérios qualificadores são aqueles considerados pelos clientes como necessários ou mínimos. Estes são os aspectos da competitividade nos quais o desempenho da produção deve estar acima de um nível determinado para, pelo menos, ser 
considerado pelo cliente. E os critérios menos importantes, como o nome indica, são relativamente pouco importantes quando comparados a outros. Dificilmente os consumidores os consideram quando tomam as suas decisões de compra. (SLACK, 1993).

Para Betto, Ferreira e Talamini (2010), a manufatura deve suportar a organização no alcance da vantagem competitiva, a qual é conseguida por meio do gerenciamento adequado dos seus recursos. Ainda segundo os referidos autores, a manufatura deve ser utilizada como arma competitiva poderosa dentro da organização, não podendo ser encarada como um mal necessário. Assim, deve contribuir com eficácia e não só com eficiência em custos, pois a avaliação do desempenho de uma fábrica apenas pelo seu custo e eficiência deve ser questionada. É necessário avaliar outras dimensões, como qualidade, confiabilidade e flexibilidade.

Nesse sentido, a moderna manufatura competitiva deve ter foco voltado à excelência e ao que realmente importa na organização, além de ser proativa e não reativa em suas ações e decisões. (ANDRADE; JUNQUEIRA, 2010; CAMPOS; SOUZA;ARAUJO, 2010; NETO; FENSTERSEIFER;FORMOSO,2003).Além disso, pode contribuir para a competitividade da organização nos seguintes aspectos: fazer produtos gastando menos que os concorrentes; fazer produtos melhores que os concorrentes; produzir mais rápido que o concorrente; entregar produtos nos prazos prometidos; e capacidade de mudança rápida no que está fazendo. Em relação aos concorrentes, Slack et al. (2006) afirmam que a operação de uma empresa pode ser muito superior, porém pode não estar atendendo às necessidades do consumidor.

\subsection{Análise competitiva de operações}

Analisar a concorrência não significa que a organização será igual ou seguirá os mesmos passos, já que uma organização pode escolher competir de uma forma diferente dos rivais, e, assim distinguir-se em relação a sua estratégia competitiva. (DIEL; GONÇALO, R. C.; MARTINS, 2001; RIEG; SCRAMIM; ROIO, 2012). Acrescenta Betto, Ferreira e Talamini (2010) que os concorrentes são pontos de comparação em relação aos quais a organização pode julgar seu desempenho.

Desse modo, a importância e desempenho das operações precisam ser considerados. (FERNANDES,2012; UMEDA et al.,2010). Os benefícios da competição são vários, entre eles, acabar com os desperdícios e otimizar as atividades que agregam valor, por meio do aumento de visibilidade e eficácia de todo sistema. Além disso, os autores chamam atenção para o benchmarking, que é o processo contínuo de medir produtos, serviços ou processos em relação aos concorrentes mais fortes ou líderes internacionais reconhecidos do setor.

Para Paiva, Carvalho Jr. e Fernsterseifer (2009), os objetivos de desempenho são denominados critérios competitivos, os quais são definidos como um conjunto de prioridades que a empresa elege para competir no mercado. Nesse sentido, em função do grau de concorrência e do tipo de mercado que deseja atuar, é necessário definir critérios competitivos, aproveitando as competências e as oportunidades com intuito de se tornar competitiva. (CORDEIRO, 2008; SENTANI; SANTOS, 2009). 
A matriz de importância $x$ desempenho envolve duas dimensões: uma delas referese à importância relativa dada pelos clientes aos critérios de desempenho, utilizando uma escala de nove pontos; e a outra envolve uma classificação, também com uma escala de nove pontos, do desempenho de cada objetivo contra os níveis de desempenho atingidos pelos concorrentes.

Ainda, a matriz é dividida em quatro zonas: urgência, aprimorar, adequado e excesso, que permitem localizar cada um dos critérios avaliados quanto à importância atribuída pelo cliente e quanto ao desempenho percebido por ele no mesmo critério. Os componentes da escala de importância são: (i) Critérios ganhadores de pedido: critérios de maior importância para o cliente, baseado neles o cliente toma uma decisão positiva ou negativa na hora da compra; (ii) Critérios qualificadores de pedido: critérios mínimos necessários para que o cliente possa considerar um produto como possível candidato na hora da compra; (iii) Critérios menos relevantes: critérios de menor importância para o cliente, esses critérios não influenciarão na decisão de compra.Já os itens que constituem a escala de desempenho são os seguintes: melhor que a concorrência, igual à concorrência e pior do que a concorrência.

Esses critérios são alocados em regiões dispostas na matriz, conforme a figura 1 . A região de ação urgente significa que critérios localizados nessa área possuem grande importância para cliente e o desempenho é baixo. De maneira inversa, a zona de excesso indica fatores de pouca importância para o cliente nos quais o desempenho percebido é alto.Já a zona de aprimoramento indica fatores consideradosimportantes e nos quais o desempenho está um pouco abaixo da média, e a área de adequação é a região ideal para todos os critérios. (CYRNE; DULLIUS, 2008).

Segundo Slack et al. (2006), é necessário determinar quais são as prioridades de melhoramentos que uma organização deve focar e qual a importância relativa dos objetivos de desempenho em relação aos consumidores, por meio de fatores competitivos ganhadores de pedido, qualificadores de pedido e menos importantes.

Figura 1: Matriz de Importância e Desempenho

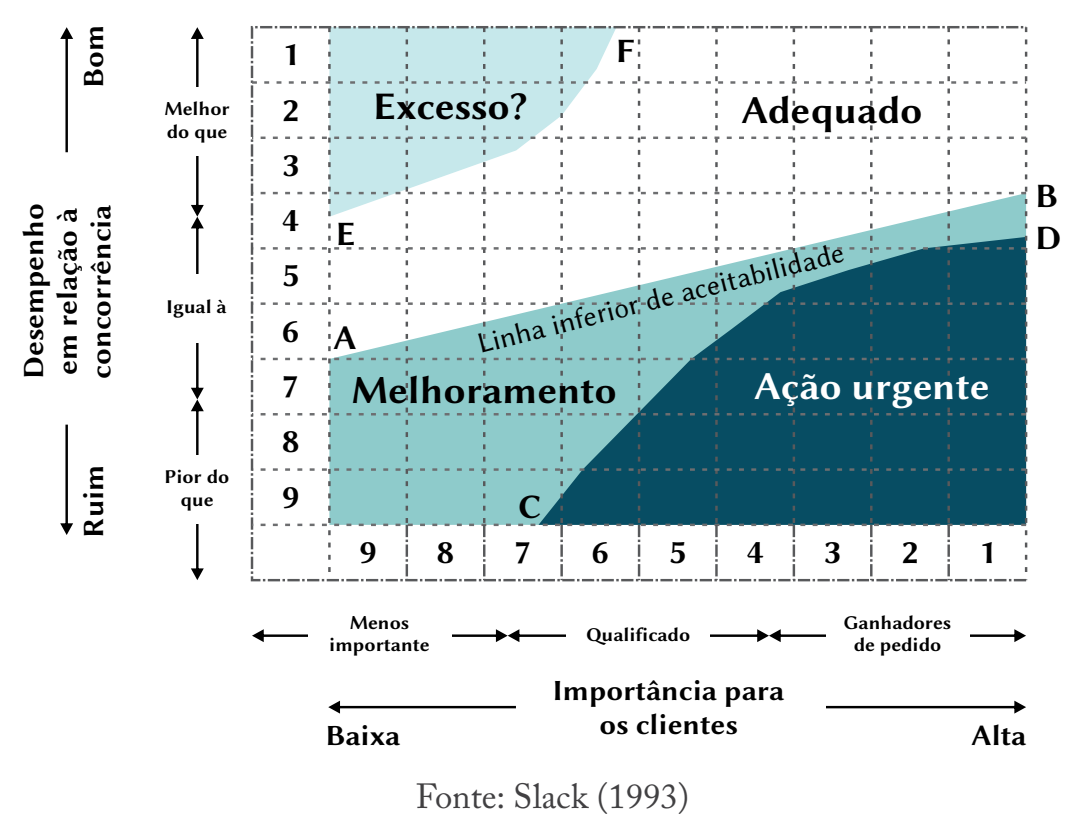


De acordo com os autores, os critérios ganhadores de pedidos podem oferecer desempenho melhor do que a concorrência, aumentando a competitividade da organização.Já nos critérios qualificadores, o desempenho da organização deve estar acima de um padrão determinado, a fim de que ele seja considerado pelo cliente. Abaixo do nível qualificador, a empresa provavelmente nem será considerada como possível fornecedora de um pedido.

Desse modo, percebe-se que a matriz apresenta quatro zonas que implicam prioridades muito diferentes. A primeira é chamada "zona adequada”. Essa zona apresenta, na sua margem inferior, a fronteira inferior de aceitabilidade, que possibilita visualizar o nível no qual a organização não deve permanecer. Os fatores competitivos nesse nível, em curto e médio prazo,são considerados satisfatórios, porém, em longo prazo, concorrentes desejarão se mover para os limites superiores. A segunda é chamada “zona de melhoramento". Nessa, acrescenta-se que o fator competitivo que cair abaixo da zona apropriada deve ser considerado como fator a ser melhorado. Se os pontos tenderem para o lado esquerdo da matriz, com certeza precisarão de melhoramento, mas não como uma prioridade principal.

A terceira zona é chamada "zona de ação urgente”. O fator competitivo nessa zona será considerado crítico, ou seja, os fatores de desempenho são tão baixos que os negócios com os clientes podem ser perdidos. A quarta e última corresponde à "zona excessiva”, isto é, o fator competitivo nessa faixa demonstra que, eventualmente, recursos em demasia estão sendo utilizados para atingir este nível. Para um melhor entendimento, visualização e avaliação do nível de importância e do nível de desempenho dos critérios competitivos associados aos produtos, e, também, classificação dos critérios ganhadores de pedido, qualificadores e menos importante, Slack (1993) propõe uma matriz dividida tanto na horizontal como na vertical, por uma escala de nove pontos para mensurar o nível de importância e o desempenho dos critérios competitivos.

\section{MATERIAIS E MÉTODOS}

Para a realização da pesquisa, foi utilizada a abordagem quantitativa, por meio de um estudo descritivo. A pesquisa quantitativa busca entender o comportamento de determinada população por meio da elaboração de uma amostra, utilizando dados estatísticos para mensurar as respostas obtidas na coleta de dados.(SAMARA;BARROS,2007;BRYMAN, 1989). O estudo descritivo, de acordo com Mattar (2007, p. 13), “caracteriza-se por ter objetivo bem definido, procedimento formal, ser bem estruturado e dirigido para a solução de problemas ou avaliação de alternativas". Tal estudo tem por objetivo descrever as características de grupos, obtendo amostras em relação a sexo, faixa etária, escolaridade, preferências e perfil demográfico.

Quanto ao método de pesquisa, este estudo pode ser considerado uma survey. A survey visa à obtenção de informações quanto à prevalência, distribuição e inter-relação de variáveis no âmbito de uma população. (FIGUEIREDO, 2004). A pesquisa survey, segundo Babbie (1999), examina uma amostra da população e pode ter uma das três finalidades:(i) Descrição: visa descobrir a distribuição de certos traços e 
atributos da população estudada. A preocupação do pesquisador, neste caso, não é o porquê da distribuição,mas o que ela é;(ii) Explicação:visa explicar a distribuição observada. Neste caso, o pesquisador tem a preocupação do porquê da distribuição existente; (iii) Exploração: objetiva funcionar como um mecanismo exploratório, aplicado a uma situação de investigação inicial de algum tema, buscando não deixar que elementos críticos deixem de ser identificados, apresentando novas possibilidades que podem posteriormente ser trabalhadas em uma survey mais controlada.

Para realizar este trabalho, foi feito um estudo de caso com variáveis qualitativas por meio de uma pesquisa em questionário, no qual foram obtidos dados da empresa objeto de estudo e seus principais concorrentes. A amostra foi obtida a partir de uma lista de critérios competitivos, que foram indicados por clientes que já adquiriram produtos e serviços da empresa estudada. Esses critérios abrangem o comportamento e a satisfação desses clientes, desde a escolha até a decisão de compra do produto.

A pesquisa foi aplicada com vinte pessoas que são consumidores de produtos e serviços dessa empresa e que passaram por todo esse processo de pesquisa, decisão de compra e serviços pósvenda, e foi importantíssima para elencar as variáveis dos critérios competitivos. Também foi aplicado um questionário de pesquisa com dez funcionários e áreas estratégicas, como diretoria, liderança e profissionais da área de marketing e qualidade, que atuam, em seu dia a dia, buscando informações da situação do mercado e dos principais concorrentes da empresa para elaborar estratégias que contribuam para o melhor posicionamento da empresa no mercado.

Após esse processo de pesquisa, foi possível verificar alguns pontos fortes da empresa frente a seus clientes e também verificar alguns pontos em que é necessário elaborar um planejamento estratégico que possibilite o desempenho esperado pelos clientes nos critérios competitivos melhor que seus concorrentes, buscando se tornar mais competitiva no mercado de atuação da empresa em questão.

As variáveis apresentadas foram pesquisadas por meio da avaliação da importância e do desempenho atribuídas a elas pelos clientes e pelos representantes da empresa. Para isso, utilizou-se a escala padrão de Slack (1993), com variação de uma nove,no caso daimportância para os clientes, de um a três ganhadores de pedido; de quatro a seis qualificador de pedido; e de sete a nove menos importante. Já no caso de desempenho em relação à concorrência, de um a três melhor que o concorrente; de quatro a seis igual ao concorrente; e de sete a nove pior que o concorrente. Os critérios competitivos e as variáveis abordadas estão apresentados no quadro 1. 
Quadro 1: Critérios e subcritérios competitivos analisados

\begin{tabular}{|c|c|c|}
\hline Critério & Subcritério & Descrição \\
\hline Preço/Custo & Preço percebido & $\begin{array}{l}\text { Custo de produzir/Custo de entregar e } \\
\text { servir }\end{array}$ \\
\hline Velocidade & $\begin{array}{l}\text { Amplitude de horários de atendimento. } \\
\text { Cumprimento de prazos acordados. } \\
\text { Segurança no uso do produto. } \\
\text { Entrega na data prometida. }\end{array}$ & $\begin{array}{l}\text { Tempo e facilidade para ganhar a acesso a } \\
\text { operação. } \\
\text { Tempo para iniciar o atendimento. } \\
\text { Tempo para cotar preço, prazo, especificação. } \\
\text { Tempo para entregar o produto. }\end{array}$ \\
\hline Confiabilidade & $\begin{array}{l}\text { Segurança no uso do produto. } \\
\text { Entrega na data prometida. } \\
\text { Cumprimento de prazos acordados. }\end{array}$ & $\begin{array}{l}\text { Cumprimento de prazos acordados. } \\
\text { Cumprimento de promessas feitas. } \\
\text { Segurança pessoal ou de bens do cliente. } \\
\text { Manutenção do atendimento mesmo que } \\
\text { algo dê errado. }\end{array}$ \\
\hline Qualidade & $\begin{array}{l}\text { Conformidade na entrega. } \\
\text { Durabilidade. } \\
\text { Rapidez na assistência técnica. } \\
\text { Confiabilidade no funcionamento. } \\
\text { Desempenho no serviço } \\
\text { Preocupados com atendimento do cliente. }\end{array}$ & $\begin{array}{l}\text { Características acessórias do produto. } \\
\text { Tempo de vida útil do produto. } \\
\text { Probabilidade de falha do produto no tempo. } \\
\text { Conforto físico do cliente oferecido pelas } \\
\text { instalações. Clareza, riqueza, precisão e fre- } \\
\text { quência da informação. } \\
\text { Grau de capacitação técnica da operação. } \\
\text { Educação e cortesia no atendimento. } \\
\text { Atendimento atento. }\end{array}$ \\
\hline Flexibilidade & $\begin{array}{l}\text { Novas tecnologias. } \\
\text { Assistência pós-venda } \\
\text { Locais para prestação / entrega do serviço. } \\
\text { Mix. }\end{array}$ & $\begin{array}{l}\text { Habilidade de introduzir/modificar produtos, } \\
\text { mix e datas economicamente. Habilidade de } \\
\text { alterar volumes agregados de produção. } \\
\text { Amplitude de horários de atendimento, na } \\
\text { área geográfica na qual o atendimento pode } \\
\text { ocorrer. }\end{array}$ \\
\hline
\end{tabular}

Fonte: Dos autores (2014) 
Os treze anos de história da unidade da empresa estudada, situada em Gravataí, no Rio Grande do Sul,foram celebrados em 2013, com recorde de produção.A fábrica, que iniciou oficialmente sua operação em 20 de julho de 2000, com uma capacidade então instalada de sessenta mil unidades/ano, atualmente opera no ritmo de 1.350 carros/dia (63 carros por hora), em três turnos de trabalho, o que permite à unidade atingir cerca de 350 mil veículos/ano. Considerada, assim, uma das quatro fábricas mais produtivas da empresa no mundo, a unidade, responsável pela montagem atualmente dos modelos Chevrolet Onix, Prisma e Celta, acumula mais de 2,1 milhões de carros produzidos em toda a sua história. Situada em um parque junto a outras dezenove empresas que fornecem componentes e sistemas para o processo produtivo da empresa - os chamados “Sistemistas", a fábrica integra o Complexo Industrial Automotivo de Gravataí. (CIAG, 2013).

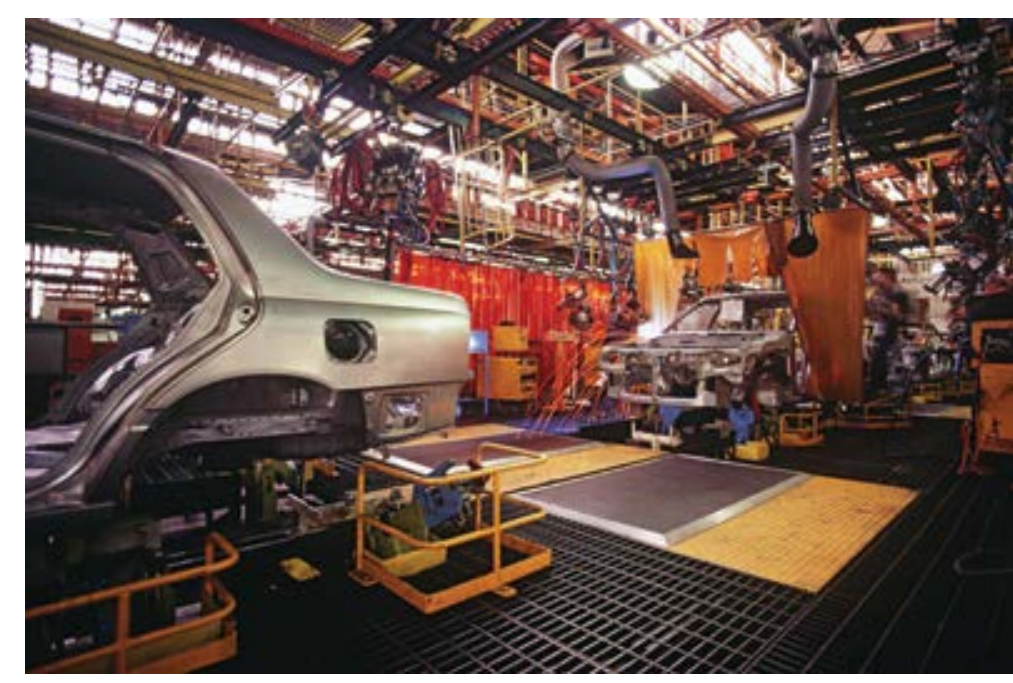

Paralelamente ao desenvolvimento da fábrica,que desde sua inauguração passou por dois expressivos processos de ampliação, o conceito de preservação do meio ambiente consolidou-secomo outrovalor chave na operação da unidade. Além de manter uma área de preservação ambiental de cinquenta hectares anexa ao complexo, desde agosto de 2012, a fábrica tornou-se a primeira unidade fabril da companhia no país a reciclar 100\% dos resíduos industriais gerados a partir do seu processo produtivo, por meio da implementação do Programa Zero Aterro. (CIAG, 2013).

\section{RESULTADOS}

Para o desenvolvimento desta pesquisa, optou-se em realizar uma pesquisa de campo na unidade da montadora situada na cidade de Gravataí, Rio Grande do Sul, com objetivo de avaliar as dimensões competitivas desta unidade. Sendo uma pesquisa quantitativa, foi utilizada para a coleta de dados uma amostra de trinta entrevistados, clientes e colaboradores da empresa pesquisada. Foram entrevistados vinte funcionários, que possuem entre 23e 36 anos, todos do sexo masculino que, além de clientes dos produtos oferecidos pela empresa, também fazem uso dos serviços de assistência técnica da mesma. Os dados coletados com esses entrevistados, por meio do questionário, foram considerados, para a pesquisa, dimensões de importância para os clientes que, posteriormente, serão tabulados na parte horizontal da matriz. Para a avaliação do desempenho da empresa frente à concorrência, foi utilizada uma amostra de dez funcionários com cargos de gestão ou lideranças de áreas estratégicas da unidade pesquisada, sendo um respondente pertencente à diretoria, três colaboradores do marketing e seis colaboradores responsáveis pela liderança na 
área de qualidade; todos do sexo masculino com idades entre trinta e quarenta anos. Os dados coletados foram, posteriormente, tabulados no eixo vertical da matriz, para verificação e análise de seu desempenho frente aos seus concorrentes.

\subsection{Avaliação da Importância}

Para a pesquisa de critérios de importância pela avaliação dos clientes, desenvolveu-se um questionário de múltipla escolha com vinte questões, utilizando os critérios de competitividade e, para cada resposta dada, foi atribuída uma escala de importância de um a nove; sendo de um a três ganhadores de pedidos, ou seja, os critérios mais relevantes para os clientes; de quatro a seis, os critérios qualificadores, segundo opinião dos clientes; e, de sete a nove, ficaram os critérios considerados menos importantes para os clientes. A classificação dos critérios de escala foi feita com base na escala de nove pontos desenvolvida por Slack (1993).

Os critérios de competitividade escolhidos para a formatação do questionário de pesquisa foram considerados de maior importância pelos monitores da pesquisa.As questões foram escolhidas por acreditar-se que, assim, é possível ter uma avaliação ampla dos produtos oferecidos no mercado pela empresa estudada, avaliação do atendimento oferecido ao cliente no momento da venda e na prestação de serviço de pós-venda.

As questões foram: 1 - Conformidade na entrega; 2 - Novas tecnologias; 3 -Durabilidade; 4 - Entrega na data prometida; 5 - Entrega quando o cliente quer; 6 - Marca; 7 - Rapidez na assistência técnica; 8 - Segurança no uso do produto; 9 - Confiabilidade de funcionamento; 10 - Desempenho de serviço; 11 - Locais para prestação e entrega de serviço; 12 - Acesso ao serviço; 13 - Preço percebido; 14 - Preocupados com o entendimento do cliente; 15 - Assistência pós-venda; 16 - Cumprimento dos prazos acordados; 17 - Confiabilidade de entrega; 18 - Amplitude de horários de atendimento 19 Manutenção do atendimento; e 20 - Tempo para iniciar o atendimento. O questionário em questão está apresentado no quadro 2. 
Quadro 2: Questionário sobre Importância

\begin{tabular}{|c|c|c|c|c|c|c|c|c|c|}
\hline \multirow[t]{2}{*}{ Questionário ao Cliente } & \multicolumn{3}{|c|}{$\begin{array}{c}\text { Ganhador de } \\
\text { pedido }\end{array}$} & \multicolumn{3}{|c|}{ Qualificador } & \multicolumn{3}{|c|}{$\begin{array}{c}\text { Menos } \\
\text { importante }\end{array}$} \\
\hline & 1 & 2 & 3 & 4 & 5 & 6 & 7 & 8 & 9 \\
\hline 1. Conformidade na entrega & & & & & & & & & \\
\hline 2. Novas tecnologias & & & & & & & & & \\
\hline 3. Durabilidade & & & & & & & & & \\
\hline 4. Entrega na data prometida & & & & & & & & & \\
\hline 5. Entrega quando o cliente quer & & & & & & & & & \\
\hline 6. Marca & & & & & & & & & \\
\hline 7. Rapidez na assistência técnica & & & & & & & & & \\
\hline 8. Segurança no uso do produto & & & & & & & & & \\
\hline 9. Confiabilidade de Funcionamento & & & & & & & & & \\
\hline 10. Desempenho de serviço & & & & & & & & & \\
\hline $\begin{array}{l}\text { 11. Locais para prestação e entrega do } \\
\text { serviço }\end{array}$ & & & & & & & & & \\
\hline 12. Acesso ao serviço & & & & & & & & & \\
\hline 13. Preço percebido & & & & & & & & & \\
\hline $\begin{array}{l}\text { 14. Preocupados com entendimento do } \\
\text { cliente }\end{array}$ & & & & & & & & & \\
\hline 15. Assistência pós-venda & & & & & & & & & \\
\hline 16. Cumprimento dos prazos acordados & & & & & & & & & \\
\hline 17. Confiabilidade de entrega & & & & & & & & & \\
\hline 18. Amplitude de horário de atendimento & & & & & & & & & \\
\hline $\begin{array}{l}\text { 19. Manutenção do atendimento, mesmo } \\
\text { diante de imprevistos }\end{array}$ & & & & & & & & & \\
\hline 20. Tempo para iniciar atendimento & & & & & & & & & \\
\hline
\end{tabular}

Fonte: Dos autores (2014) 


\subsection{Avaliação do}

\section{Desempenho}

Para avaliar o desempenho da empresa frente aos principais concorrentes, foi aplicado um questionário com vinte questões de múltipla escolha na própria unidade da empresa estudada. As questões foram respondidas por dez funcionários com cargos de lideranças na unidade, como diretores, gerentes, coordenadores e auditores de qualidade. Para as respostas obtidas nesse questionário foi atribuído o mesmo valor aplicado no questionário de clientes, com valor de escala de um a nove, conforme escala desenvolvida por Slack (1993).

As questões escolhidas para avaliação do desempenho da unidade pesquisada foram as mesmas aplicadas aos clientes. Porém, com a intenção de avaliar os critérios de competitividade sob a ótica das lideranças internas da unidade frente a seus principais concorrentes, esta avaliação serviu como base para gerar a matriz de desempenho x importância, que foi fundamental para a avaliação do desempenho da unidade frente à concorrência. $\mathrm{O}$ questionário de desempenho é apresentado no quadro 3.

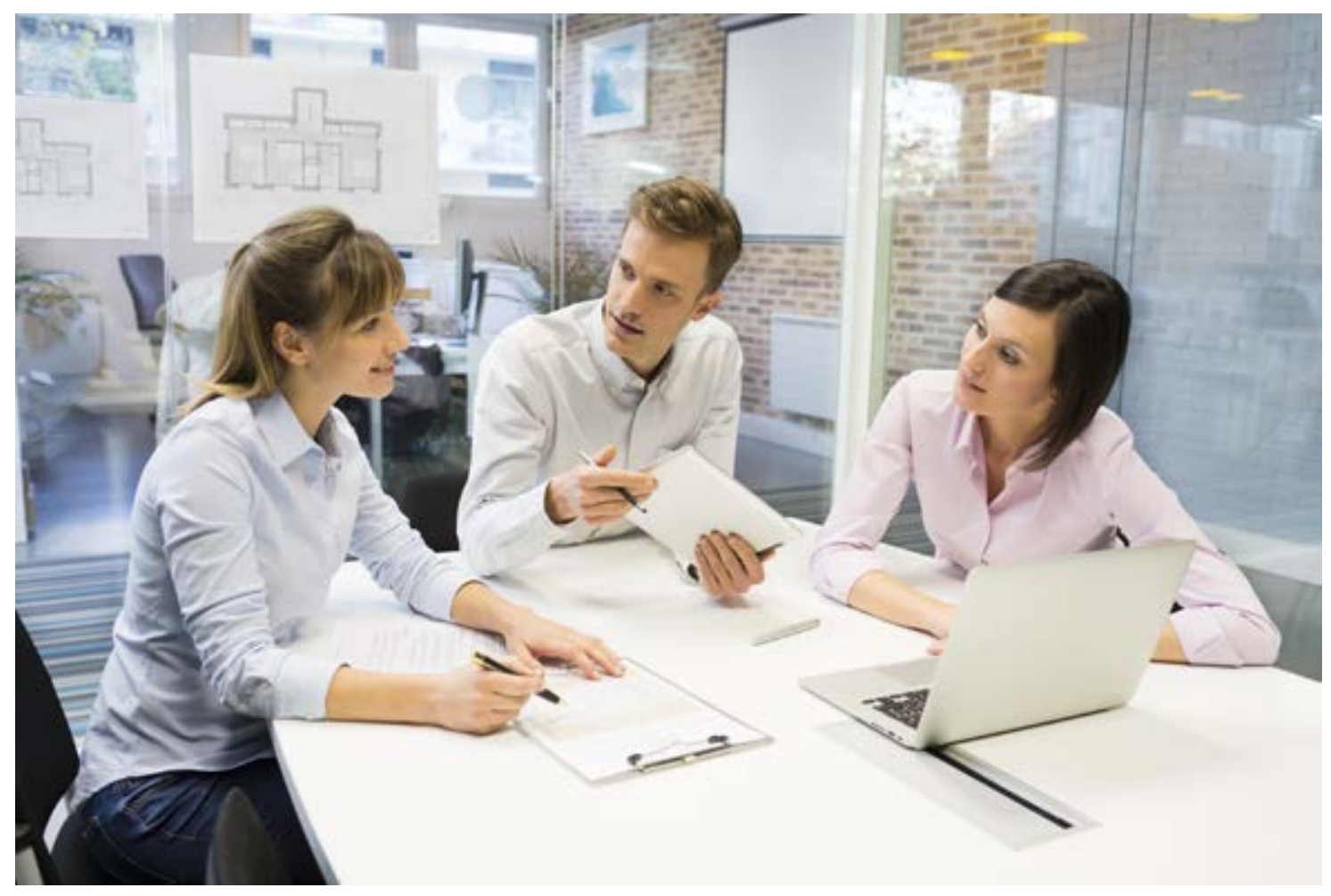


Quadro 3: Questionário de desempenho

\begin{tabular}{|c|c|c|c|c|c|c|c|c|c|}
\hline \multirow{2}{*}{$\begin{array}{l}\text { Questionário de desempenho interno em } \\
\text { relação aos principais concorrentes }\end{array}$} & \multicolumn{3}{|c|}{$\begin{array}{l}\text { Melhor que os } \\
\text { concorrentes }\end{array}$} & \multicolumn{3}{|c|}{$\begin{array}{c}\text { Igual aos } \\
\text { concorrentes }\end{array}$} & \multicolumn{3}{|c|}{$\begin{array}{c}\text { Pior que os } \\
\text { concorrentes }\end{array}$} \\
\hline & 1 & 2 & 3 & 4 & 5 & 6 & 7 & 8 & 9 \\
\hline \multicolumn{10}{|l|}{ 1. Conformidade na entrega } \\
\hline \multicolumn{10}{|l|}{ 2. Novas tecnologias } \\
\hline \multicolumn{10}{|l|}{ 3. Durabilidade } \\
\hline \multicolumn{10}{|l|}{ 4. Entrega na data prometida } \\
\hline \multicolumn{10}{|l|}{ 5. Entrega quando o cliente quer } \\
\hline \multicolumn{10}{|l|}{ 6. Marca } \\
\hline \multicolumn{10}{|l|}{ 7. Rapidez na assistência técnica } \\
\hline \multicolumn{10}{|l|}{ 8. Segurança no uso do produto } \\
\hline \multicolumn{10}{|l|}{ 9. Confiabilidade de funcionamento } \\
\hline \multicolumn{10}{|l|}{ 10. Desempenho de serviço } \\
\hline \multicolumn{10}{|l|}{$\begin{array}{l}\text { 11. Locais para prestação e entrega do } \\
\text { serviço }\end{array}$} \\
\hline \multicolumn{10}{|l|}{ 12. Acesso ao serviço } \\
\hline \multicolumn{10}{|l|}{ 13. Preço percebido } \\
\hline \multicolumn{10}{|l|}{$\begin{array}{l}\text { 14. Preocupados com entendimento do } \\
\text { cliente }\end{array}$} \\
\hline \multicolumn{10}{|l|}{ 15. Assistência pós-venda } \\
\hline \multicolumn{10}{|l|}{ 16. Cumprimento dos prazos acordados } \\
\hline \multicolumn{10}{|l|}{ 17. Confiabilidade de entrega } \\
\hline \multicolumn{10}{|l|}{ 18. Amplitude de horário de atendimento } \\
\hline \multicolumn{10}{|l|}{$\begin{array}{l}\text { 19. Manutenção do atendimento, mesmo } \\
\text { diante de imprevisto }\end{array}$} \\
\hline 20. Tempo para iniciar atendimento & & & & & & & & & \\
\hline
\end{tabular}

Fonte: Dos autores (2014) 


\section{ANÁLISE E DISCUSSÃO DOS RESULTADOS}

Após a aplicação dos questionários, foi verificado se todos os questionários respondidos estavam com o seu preenchimento adequado e válidos para serem tabulados na pesquisa. A apuração do resultado das vinte questões foi feita somando-se todos os valores encontrados para cada uma das questões aplicadas, e, posteriormente, encontrando a média para cada uma das vinte questões aplicadas.

Nesta etapa, se fez necessário a utilização de regra de arredondamento para encontrarmos valores inteiros para melhor visualização na matriz. Primeiramente, os valores encontrados foram colocados em uma tabela (tabela 1), que faz relação entre importância (média das respostas dos clientes) e desempenho (média das respostas dos líderes da empresa estudada) para, posteriormente, serem aplicados na matriz e realizada a verificação dos resultados. As questões foram colocadas na tabela na mesma ordem dos questionários, todavia, para uma melhor visualização na matriz,foram ordenadas em ordem alfabética, por exemplo, questão 1 igual à questão A e, assim, respectivamente.

Tabela 1: Relação Importância x Desempenho

\begin{tabular}{|c|c|c|}
\hline \multirow{2}{*}{ Subcritérios } & \multicolumn{2}{|c|}{ Avaliação } \\
\hline & Importância & Desempenho \\
\hline A. Conformidade na entrega & 4 & 4 \\
\hline B. Novas tecnologias & 3 & 3 \\
\hline C. Durabilidade & 2 & 4 \\
\hline D. Entrega na data prometida & 3 & 5 \\
\hline E. Entrega quando o cliente quer & 3 & 6 \\
\hline F. Marca & 4 & 2 \\
\hline G. Rapidez na assistência técnica & 3 & 5 \\
\hline H. Segurança no uso do produto & 2 & 4 \\
\hline I. Confiabilidade de funcionamento & 2 & 3 \\
\hline J. Desempenho de serviço & 4 & 5 \\
\hline K. Locais para prestação e entrega do serviço & 4 & 5 \\
\hline L. Acesso ao serviço & 4 & 5 \\
\hline
\end{tabular}




\begin{tabular}{l|c|c}
\hline M. Preço percebido & 3 & 5 \\
\hline N. Preocupados com entendimento do cliente & 3 & 5 \\
\hline O. Assistência pós-venda & 3 & 5 \\
\hline P. Cumprimento dos prazos acordados & 3 & 5 \\
\hline Q. Confiabilidade de entrega & 4 & 5 \\
\hline R. Amplitude de horário de atendimento & 6 & 5 \\
\hline S. Manutenção do atendimento, mesmo diante de & 4 & 5 \\
\hline imprevisto & 4 & 5 \\
\hline
\end{tabular}

Fonte: Dos autores (2014)

Em relação aos resultados encontrados nas respostas sobre os critérios de competitividade, para os clientes, os itens novas tecnologias; $\mathrm{du}^{-}$ rabilidade; entrega na data prometida; entrega quando o cliente quer; rapidez na assistência técnica; segurança no uso do produto; confiabilidade de funcionamento; preço percebido; preocupados com o entendimento do cliente; assistência pós-venda e cumprimento dos prazos acordados foram considerados pela pesquisa como ganhadores de pedidos.

Os itens conformidade de entrega; marca; desempenho de serviço; locais para prestação e entrega de serviço; acesso ao serviço; confiabilidade de entrega; e manutenção do atendimento mesmo diante de imprevistos e tempo para iniciar o atendimento foram considerados como critérios qualificadores. O item amplitude de horário de atendimento foi considerado o menos importante.
Para os mesmos critérios, de acordo com o resultado da avaliação de desempenho frente aos concorrentes, os resultados foram os seguintes: os itens novas tecnologias; marca; e confiabilidade de funcionamento, foram considerados melhores que os concorrentes. Os itens conformidade na entrega; durabilidade; entrega na data prometida; rapidez na assistência técnica; segurança no uso do produto; desempenho de serviço; locais para prestação e entrega de serviço; acesso ao serviço; preço percebido; preocupados com o entendimento docliente; assistência pós-venda; cumprimento dos prazos acordados; confiabilidade de entrega; amplitude de horário de atendimento; e manutenção do atendimento mesmo diante de imprevistos e tempo para iniciar atendimento foram considerados itens com desempenho igual aos concorrentes. Não foram classificados pela pesquisa itens considerados pior que a concorrência. A configuração da matriz é apresentada na figura 2 . 


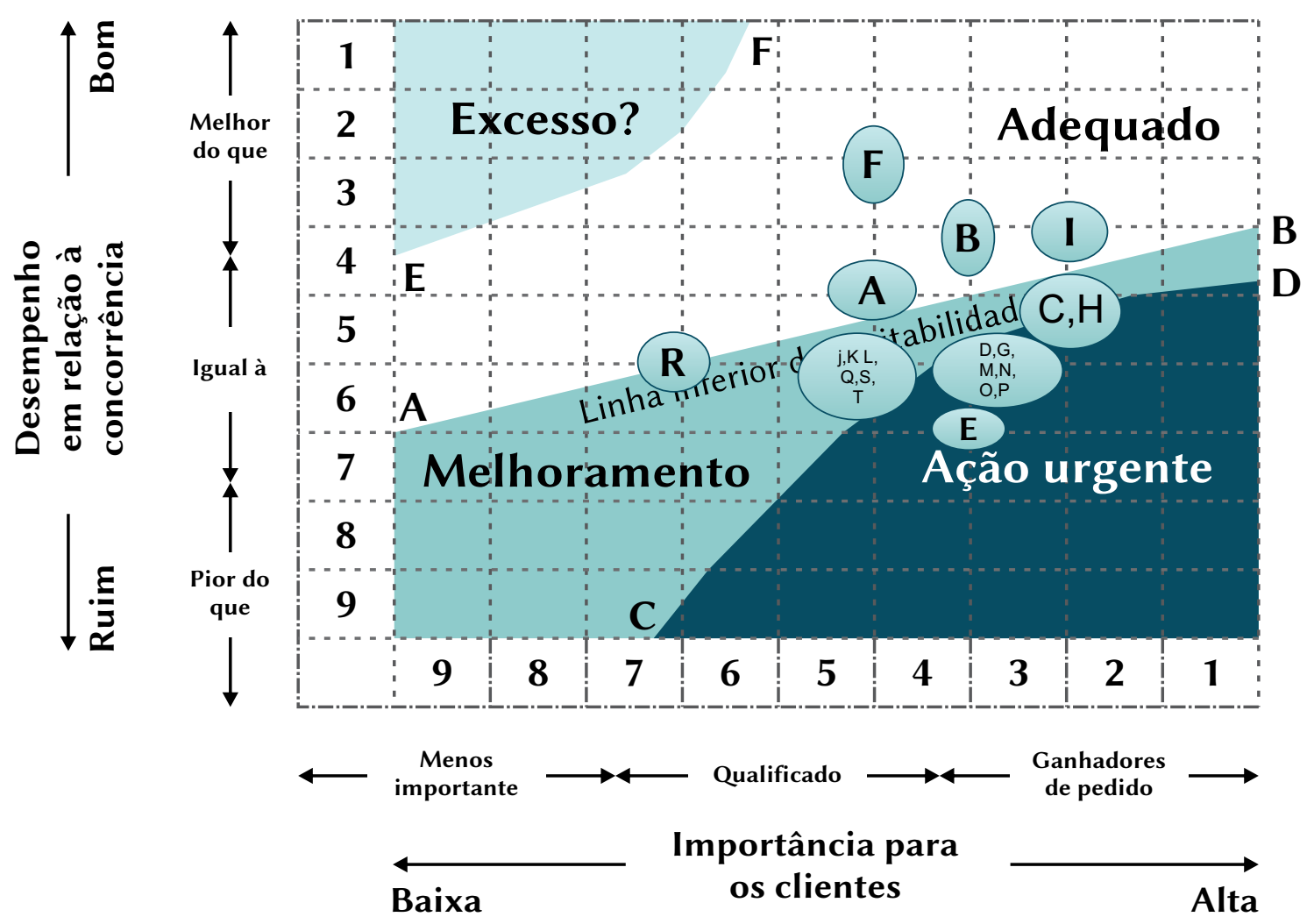

Fonte: Dos autores (2014)

Com o cruzamento dos dados na matriz, foi possível observar quais fatores de competitividade deveriam, a priori, ter ações de melhoria urgente, quais fatores devem ser melhorados, quais já estão em níveis adequados e quais estão em níveis de excesso. Para esta pesquisa, os critérios de competitividade que ficaram na zona de ação urgente foram: entrega na data prometida; entrega quando o cliente desejar; rapidez na assistência técnica; preço percebido; preocupados com o entendimento do cliente; assistência pós-venda; e cumprimento dos prazos acordados. Para esses critérios, a empresa estudada deveria ter uma tomada de ação urgente para o melhoramento frente aos seus concorrentes, sobretudo por serem todos itens classificados como ganhadores de pedidos pelos clientes deste mercado caracterizado por forte concorrência.
Os critérios ganhadores de pedidos devem ser sempre prioridades em um plano de ação. Foram considerados que, dentre os itens que estão na zona de ação urgente, os itens com prioridade de um plano de ação foram: entrega na data prometida; entrega quando o cliente desejar; cumprimento dos prazos acordados; e preço percebido. Primeiramente, deve-se verificar os motivos das entregas não estarem sendo feitas dentro dos prazos acordados com os clientes, controlar o fluxo da cadeia de suprimentos e das operações para encontrar onde a empresa está enfrentando gargalos que estão a impedindo de ser eficiente nas entregas, e, assim, fazer as correções necessárias para que tudo aconteça dentro do esperado e da forma que foi acordado com o cliente.

Quanto ao preço percebido, possíveis alternativas à empresa seriam verificar novas tecnologias que possam baixar o custo da produção, 
encontrar novas opções de matérias-primas, equipamentos e máquinas mais eficientes, fornecedores e parceiros de negócios que atendem às necessidades da empresa e observar se os demais custos que compõem o preço final das mercadorias oferecidas estão de acordo com o esperado.

Os demais itens que ficaram na zona de ação urgente também têm muita importância e, basicamente, referem-se ao pós-venda. Tais critérios competitivos foram: rapidez na assistência técnica; confiabilidade de uso; preocupados com o entendimento do cliente; e assistência técnica. Nesse último item, a empresa deveria investir em capacitação dos seus credenciados para melhorar os processos de atendimento e esclarecer aos clientes suas dúvidas sobre o funcionamento do veículo. Também poderia cobrar que os prazos prometidos aos clientes para os consertos fossem claros e cumpridos e, com certeza, para ampliar os pontos de atendimentos de assistência, pois somente dessa forma ganharia mais mercado e conquistaria mais clientes do que seus concorrentes.

Os critérios de competitividade que ficaram na zona de melhoramento foram: durabilidade e segurança no uso do produto; itens que devem ser reavaliados pela engenharia de produtos e qualidade desta empresa, pois são itens importantes, considerados pelos clientes como ganhadores de pedido.

Já os critérios de competitividade (desempenho do serviço, locais para prestação e entrega do serviço, acesso ao serviço, confiabilidade de entrega, manutenção do atendimento, mesmo diante de imprevistos e tempo para iniciar o atendimento) fazem referência à assistência técnica e pós-vendas. Conforme já foi analisado na zona de ação urgente, o serviço de pós-venda e assistência técnica deve ser melhorado junto aos credenciados. Uma possível alternativa seria a ampliação da quantidade de pontos de atendimento ao cliente, incluindo a verificação junto à rede credenciada, e um atendimento de socorro diante de imprevistos. Deve-se, portanto, avaliar alternativas para atender a essa necessidade, pois tais critérios competitivos foram considerados pelos clientes como qualificadores. Em determinados casos, a depender da necessidade de cada cliente, tal critério pode se tornar determinante para a decisão de compra.

O critério amplitude no horário de atendimento foi considerado como um critério menos importante. $\mathrm{O}$ plano de ação para melhorar tais critérios deve ser avaliado e priorizado de acordo com o grau de importância dado pelos clientes, uma vez que os critérios foram avaliados pelo desempenho como sendo igual à concorrência.

Os critérios de competitividade que ficaram classificados na zona de adequados foram: conformidade e entrega, novas tecnologias, marca e confiabilidade de funcionamento. Todos os itens foram classificados pelos clientes como sendo ganhadores de pedido, tendo desempenho melhor que os concorrentes. Uma exceção foi o critério conformidade e entrega, que foi considerado como qualificador de pedido pelos clientes e está no mesmo nível de desempenho que a concorrência. Os outros critérios, além de ganhadores de pedidos, foram avaliados pelo desempenho como melhores do que a concorrência. Esses itens são importantes para uma empresa, pois são considerados para esta pesquisa como pontos fortes, que poderiam ser utilizados como fatores de diferenciação em campanha de marketing, por exemplo, após a efetivação das ações de melhoria.

$\mathrm{Na}$ zona de excesso, não ficaram classificados critérios de competitividade, o que mostra que a empresa não está empregando esforços de gestão desnecessários em algum item. Os critérios que 
ficaram classificados nas zonas de ação urgente e melhoramento, nesta pesquisa,são os mesmos considerados pela avaliação de desempenho como iguais à concorrência. Portanto, tendo em vista os objetivos iniciais da pesquisa, foi possível verificar ser relevante a aplicação da matriz de importância $\mathrm{x}$ desempenho para avaliar a competitividade da montadora em questão. A discussão trouxe elementos de análise importantes sob a ótica da competitividade. Além disso, conclui-sequepossuirumposicionamento comoigual à concorrência não é suficiente e, atualmente, não está satisfazendo as necessidades e expectativas dos clientes deste mercado.

\section{CONCLUSÃO}

Com esta pesquisa, propôs-se avaliar a satisfação dosclientesdeuma montadoradeautomóveis,bem como verificar se o desempenho da empresa está atendendo às expectativas e necessidades desses clientes,e,ainda,analisarodesempenhoda empresa diante de seus concorrentes. Foi possível encontrar alguns critérios competitivos com deficiências de desempenho e sugerir ações de melhoria em seus processos e, assim, obter um melhor posicionamento no mercado em que está inserida.

Por meio da avaliação dos critérios de competitividade sob as duas óticas, cliente e desempenho interno, foi possível verificar claramente os critérios de maior importância e ganhadores de pedidos para os clientes e como o desempenho desses critérios estavam em relaçãoà concorrência. Também foi possível identificar os pontos em que a empresa deve melhorar (zona de ação urgente e melhoramento), e os pontos nos quais a empresa está acertando (zona de adequado).

Os critérios avaliados pelos clientes como sendo ganhadores de pedidos e que ficaram classificados na zona de ação urgente na matriz foram: entrega na data prometida, entrega quando o cliente desejar, rapidez na assistência técnica, preço percebido, preocupados com o entendimento do cliente, assistência pós-venda, e cumprimento dos prazos acordados.
Esses critérios deveriam ser considerados pela empresa como prioridade para a gestão estratégica para assim melhorar a competitividade.

Entre os nove critérios que ficaram classificados na zona de melhoramento, dois são ganhadores de pedido, durabilidade e segurança no uso do produto; seis são critérios qualificadores para os clientes, desempenho do serviço, locais para prestação e entrega do serviço, acesso ao serviço, confiabilidade de entrega, manutenção no atendimento, tempo para iniciar atendimento; e somente um critério foi considerado de menos importância, amplitude de horário de atendimento.

E pela avaliação de desempenho, esses critérios estão em um patamar de igualdade em relação à concorrência. Logo, para esses critérios, devese desenvolver um plano de ação conforme a classificação de cada um, levando-se em conta a importância deles para o cliente. Os critérios avaliados na zona adequada foram somente quatro, mas de suma importância para a competitividade nesse mercado. Esses critérios foram considerados pontos fortes da empresa estudada (conformidade de entrega, novas tecnologias, marca e confiabilidade de funcionamento), podendo ser utilizados para fazer uma campanha de marketing após a execução do plano de ação 
traçado pela empresa para a melhoria de sua avalição.

Ainda, foi possível concluir que a empresa estudada possui diversos aspectos competitivos a serem melhorados para se tornar um concorrente mais forte no mercado. Isso porque foi considerada pela avaliação de desempenho na maioria dos itens como igual à concorrência. Logo, um plano de ações estratégicas será necessário para atender com maior eficiência às expectativas e necessidades dos seus clientes.

Concluímos que a pesquisa atingiu os objetivos esperados inicialmente, pois foi possível evidenciar a posição atual da empresa na relação cliente e concorrência. A presente pesquisa pode ser levada em consideração para uma tomada de decisão pelos gestores, sendo um norteador do caminho a ser seguido pelo plano de ação. Considera-se necessário ressaltar a importância desse tipo de pesquisa para as empresas que querem permanecer no mercado, uma vez que conhecer o seu cliente, medir o desempenho de seus produtos e serviços em relação aos concorrentes mais fortes se faz necessário. Trabalhos futuros podem ser realizados em outras montadoras do país, de forma a comparar os resultados da competitividade dos líderes do setor automotivo nacional. 


\section{EVALUATION OFTHE COMPETITIVENESS OF PRODUCTS AND SERVICES OF A CAR BUILDER}

\begin{abstract}
This article aims to verify the applicability of the importance and performance matrix in a multinational firm of the automotive sector. Therefore, competitive criteria, considered important by customers, and the company'sperformancefor thesecriteria were analyzed. The survey was conducted with consumers who have purchased products and services and professionals of strategic areas of the company. Data were collected through semi-structured questionnaires in which we sought to identify the importance and the performance in the perception of customers and of the company, in the variables that make up each competitive criterion. The main results of the research demonstrated that the criteria evaluated by customers as winners of requests that were classified in the urgent action zone in the matrix were: delivery at the promised date, delivery when the customer wants, timely technical assistance, perceived price, preoccupation with understanding the customer, after sales assistance and compliance with the agreed deadlines. Such criteria, therefore, should be a priority for the company in defining actions to improve competitiveness.
\end{abstract}

Keywords: Competitive

Criteria. Importance.

Performance.

\section{REFERÊNCIAS}

ANDRADE, M.; JUNQUEIRA, A. G. W. Gestão de produção: Utilização da Matriz importânciadesempenho em uma indústria de ação de aves. Revista Destaque Acadêmico, ano 2, n. 1, 2010.

ARAUJO, A. N. B. et al. Planejamento estratégico como diretriz para a estratégia de produção: Aplicação em uma fábrica de cachaça artesanal. In: Encontro Nacional de Engenharia de Produção, XXXI, Belo Horizonte, MG, Brasil, 2011.

BABBIE, Earl. Métodos de Pesquisas de Survey. Belo Horizonte: Ed. UFMG, 1999, 519 p.

BETO, L.; FERREIRA, G. M. V; TALAMINI, E. Aplicação da matriz importância-desempenho no varejo de alimentos: Caso no Rio Grande do Sul. Revista da Micro Empresa, Campo Limpo paulista v. 4, n. 2, p. 64-79, 2010.

BRYMAN, Alan. Research Methods and Organization Studies. Great Britain: Routledge, 1989, $283 \mathrm{p}$.

CAMPOS, A. C. C. F.; SOUZA, D. M. O.; ARAUJO, E. P. Competitividade no setor de educação superior no $\mathrm{RN}$ : uma abordagem integrada da GQT, TI e estratégia competitiva. Anais... Cobenge, 2003.

CIAG. Disponível em: <http://www.ciag.com.br/>. Acesso em: 10 out. 2013.

CYRNE, C. C. S.; DULLIUS, R. A matriz importância $\mathrm{x}$ desempenho aplicada a uma instituição de ensino superior. Universidade Federal de Santa Catarina, dezembro, 2008.

CORDEIRO, J. B. M. Avaliando o desempenho do sistema produtivo: formalização de um método para construção de scorecards para a área de operações. Revista FAE, Curitiba, v. 11, n. 1, 79-94, jan./jun. 2008.

DIEHL, C. A.; GONÇALO, R. C.; MARTINS, G. A. Dimensões competitivas em organizações de serviços: Um modelo de pesquisa aplicada. Universidade do Vale dos Sinos, São Leopoldo, RS, 2001.

FERNANDES, C. G. Aplicação da Matriz Importância x Desempenho de Slack na Análise de Mercado em uma Indústria e domissanitários. Especialize Revista On Line, maio de 2012. 
FIGUEIREDO, Nebia Maria Almeida. Método e metodologia na pesquisa científica. São Paulo: Yendis, 2004.

FINE, C. H.; HAX, A. C., Manufacturing Strategy: A Methodology and an Illustration, Interfaces, v. 15, n. 6, 1985 .

FUSCO, J. P. A. Comportamento do Consumidor versus estratégia de operações a ponte Clienteempresa. ERA - Revista de Administração de Empresas, São Paulo, v. 35, n. 4, p. 42-51, agosto de 1995.

HAYES,R.H.; WHEELWRIGHT,S.C.

Restoring our Competitive Edge-Competing

Through Manufacturing, Jhon Wiley \& Sons, Inc., USA, 1984.

\section{KOTLER, P. Administração de marketing: a} edição do novo milênio.

São Paulo: Prentice Hall, 2000.

MATTAR, F. N. Pesquisa de marketing: edição compacta. 4. ed. São Paulo: Atlas, 2007.

MORILHAS, L. J. Estratégia de operações utilização da Matriz Importância x

Desempenho: Um setor sucro-alcooleiro, Universidade de São Paulo. Anais: X Semead, 2007.

NETO, J. P. B.; FENSTERSEIFER, J. V.; FORMOSO, C. T. Os critérios competitivos da produção: Um estudo exploratório na Construção de edificações. Revista RAC, v. 7, n. 1, 2003.

PAIVA; E. L.; CARVALHO JR., J. M. de; FENSTERSEIFER, J. E. Estratégia de Produção e Operações: Conceitos, Melhores Práticas, Visão de Futuro. 2. ed. Bookman, 2009.

PRETO, M. R. Formulação de uma nova estratégia de manufatura motivada pela mudança tecnológica. In: Encontro Nacional de Engenharia de Produção, XXIII, Ouro Preto, MG, Brasil, 2003.
RIEG, D. L.; SCRAMIM, F. C. L.; ROIO, M. L. D. Critérios competitivos e matriz importância versus desempenho: Estudo de caso em uma empresa de call center localizada na cidade de São Paulo, outubro 2013 In: Encontro Nacional de Engenharia de Produção, XXXII, Bento Gonçalves, 2012.

SAMARA, B. S.; BARROS, J. C. de. Pesquisa de marketing: conceitos e metodologia. 4. ed. São Paulo: Pearson Prentice Hall, 2007.

SENTANI, O. F.; SANTOS, F. C. A. Dimensões competitivas de recursos humanos aplicadas a gestão de uma empresa pública de pesquisa e desenvolvimento. In: SIMPOI, 2009.

SLACK, N. Vantagem competitiva em manufatura. São Paulo: Atlas, 1993.

SLACK, N. et al. Administração da Produção. Edição compacta. Revisão técnica Henrique Côrrea e Irineu Gianesi. São Paulo: Atlas, 2006.

UMEDA, W. L. et al. Método peculiar de governança corporativa por controlador Fuzzy Matriz Slack. Revista de Engenharia e Tecnologia. v. 2, n. 3, dezembro de 2010.

Data de recebimento: 28/07/14

Data de aprovação: 29/10/14 


\section{SOBRE OS AUTORES}

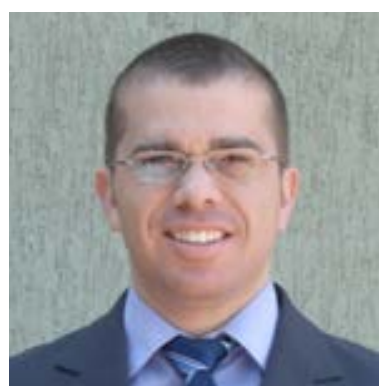

Diego Augusto de Jesus Pacheco

Doutorando em Engenharia de Produção na UniversidadeFederal do Rio Grande do Sul (UFRGS). Mestrado Acadêmico em Engenharia de Produção e Sistemas pela Universidade do Vale do Rio dos Sinos (UNISINOS). Graduado em Engenharia de Produção pela Universidade do Vale do Rio dos Sinos (UNISINOS). É professor de graduação e pós-graduação na área de Gestão de Operações. Possui artigos publicados em congressos e periódicos nacionais e internacionais na área da Gestão de Operações. É revisor dos periódicos IJPPM, IJM\&P e Gestão \& Produção e de congressos nacionais e internacionais. Atua, principalmente, nos seguintes temas: Estratégia de Operações e de Produção, Engenharia de Processos e Produto, Logística Enxuta, Teoria das Restrições, Qualidade e Inovação+Sustentabilidade.

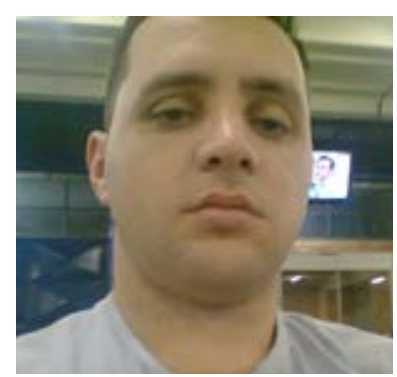

Junior Silva de

\section{Castro}

É acadêmico do curso de Administração de Empresas no Complexo de Ensino Superior de Cachoeirinha (Cesuca). Cursou Técnico em Mecânica Industrial pela Escola Técnica Estadual Parobé/RS. Atua no ramo industrial desde 2003, atuando em multinacionais como Souza Cruz, Dana Albarus e General Motors do Brasil. Atualmente é Auditor de Qualidade na General Motors do Brasil.

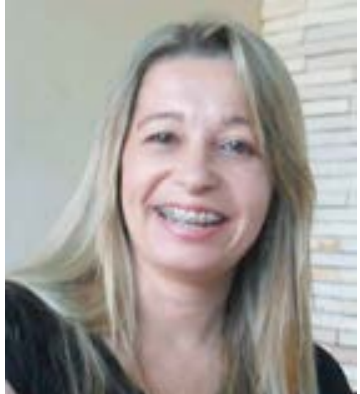

Luciana Wichruk

Morais

É acadêmica do curso de Administração de EmpresasnoComplexo de Ensino Superior de Cachoeirinha (Cesuca). Possui mais de 15 anos de experiência profissional na área de Administração de Empresas nos setores do comércio e varejo. Atualmente exerce atividades como gestora em uma grande rede varejista nacional. 